\title{
Authorship: from credit to accountability
}

\author{
Reflections from the Editors' Network
}

\author{
F. Alfonso for Editors' Network, European Society of Cardiology (ESC) Task Force
}

Published online: 20 May 2019

(C) The Author(s) 2019

\begin{abstract}
The Editors' Network of the European Society of Cardiology (ESC) provides a dynamic forum for editorial discussions and endorses the recommendations of the International Committee of Medical Journal Editors (ICMJE) to improve the scientific quality of biomedical journals. Authorship confers credit and important academic rewards. Recently, however, the ICMJE emphasised that authorship also requires responsibility and accountability. These issues are now covered by the new (fourth) criterion for authorship. Authors should agree to be accountable and ensure that questions regarding the accuracy and integrity of the entire work will be appropriately addressed. This review discusses the implications of this paradigm shift on authorship requirements with the aim of increasing awareness of good scientific and editorial practices.
\end{abstract}

Keywords Editorial ethics · Scientific process · Authorship · Accountability $\cdot$ Scientific journals $\cdot$ Journals

The Editors' Network of the European Society of Cardiology (ESC) is committed to fostering the implementation of high-quality editorial standards among ESC National Society Cardiovascular Journals (NSCJ) [1-6]. NSCJ play a major role in disseminating original scientific research worldwide, but also in education and harmonisation of clinical practice [2-6]. Promot-

This is a joint simultaneous publication initiative involving all interested National and Affiliated Cardiovascular Journals of the European Society of Cardiology (ESC).

\section{F. Alfonso $(\bowtie)$}

Cardiology Department, Hospital Universitario de La

Princesa, Instituto de Investigación sanitaria IIS-IP,

Universidad Autónoma de Madrid, Madrid, Spain

falf@hotmail.com ing editorial excellence is paramount to increasing the scientific prestige of NSCJ [1-6]. In this regard, the Editors' Network endorses the recommendations of the International Committee of Medical Journal Editors (ICMJE) [1]. The ICMJE continuously updates its document on uniform requirements (previously known as the Vancouver guidelines) for manuscripts submitted to biomedical journals. These include recommendations for the conduct, reporting, editing and publication of scholarly work. Notably, vexing ethical issues are gaining increasing editorial relevance [1].

Biomedical research relies on trust and transparency of the scientific process where authors remain centre stage [1, 7-9]. This review will discuss the new recommendations on authorship issued by the ICMJE $[1,10,11]$ with the aim of providing further editorial insight to be progressively implemented by the NSCJ.

\section{New authorship requirements}

In August 2013 an important revision of the ICMJE recommendations included a fourth criterion for authorship to emphasise each author's responsibility to stand by the integrity of the entire work $[1,10,11]$. Classically, the ICMJE requirements for authorship included: (1) substantial contributions to the conception or design of the work or the acquisition, analysis, or interpretation of data for the work; (2) drafting the work or revising it critically for important intellectual content; and, (3) final approval of the version to be published. In the updated ICMJE requirements a new (fourth) criterion also should be met [1]. This novel requirement for authorship includes agreement to be accountable for all aspects of the work and ensuring that questions related to the accuracy or integrity of any part of the work are appropriately investigated and resolved [1]. The essence of this new requirement 
is that it helps to balance credit with responsibility [10]. With this revision the ICMJE emphasises that authorship is a serious commitment to accountability. Now all four conditions must be met by each individual author [1]. The addition of a fourth criterion was motivated by situations in which some authors were unable to, or refused to, respond to inquiries on potential scientific misconduct regarding certain aspects of the study or by denying any responsibility [1, 10-14]. Editors occasionally face reluctant authors who try to distance themselves from a conflictive publication and shift responsibilities elsewhere [11]. The main novel idea is to emphasise the responsibility of each author to stand for the integrity of the entire work. Each author of a scientific paper needs to understand the full scope of the work, know which coauthors are responsible for specific contributions and have confidence in co-authors' ability and integrity [1, 10-14]. Should questions arise regarding any aspect of a study, the onus is on all authors to investigate and ensure resolution of the issue, which is then to be presented to the corresponding Editor [1, 10-14].

To better appraise this fourth criterion the precise meaning of responsibility and accountability should be revisited. Responsibility is defined as the moral obligation to ensure that a particular task is adequately performed $[15,16]$. Accordingly, responsibility relates to tasks that have been assigned to an individual $[15,16]$. By contrast, accountability denotes the duty to justify a given action to others and to respond for the results of that action $[15,16]$. Therefore, accountability mainly relates to the awareness and assumption of the role of being the one to blame if things go wrong $[15,16]$. Nevertheless, oftentimes responsibility is used interchangeably with accountability $[15,16]$.

Claiming that each individual author is held morally responsible in every case that misconduct is detected would appear unreasonable considering the complexity of current research. Rather, the fourth criterion suggests that each author must cooperate to clarify misconduct-related issues if the paper is called into question $[1,16]$.

\section{Research credits}

Acceptance and publication of a scientific paper is always a cause of major celebration among authors [11]. Authorship provides prestige, credit and scientific recognition. Authorship has important academic, social and financial implications [1, 11]. Currently, authorship remains a major criterion for promotion and career advancement among scholars. Publication records are revised in depth for university tenures and job appointments. Total number of publications and citations remain currencies widely used to ascertain the academic value of individual investigators. In this regard, the ICMJE recommendations on authorship are intended to ensure that anybody who has made a 'substantive' intellectual contribution to a paper is given credit as an author [1].

\section{Potential problems derived from publication of research}

Publication of a scientific paper usually marks the end of a research project and opens a time for discussion and criticism or acceptance by the scientific community [11]. Occasionally, the healthy scientific debate fuelled by the publication of the paper raises serious concerns. In rare cases, even the integrity of the research or published paper is brought into question [11]. In these situations authors may try to escape from the embarrassment of publishing a scientifically flawed study. This explains why the new fourth criterion is so pertinent to address issues related to scientific misconduct. Should irregularities be confirmed, editors must report to the authors' academic institution and, eventually, to the readers, with expressions of concern, or, in the worst-case scenario, with a retraction of the published paper [1].

\section{Considerations on classical authorship criteria}

Any researcher listed as an author should have made a 'substantive' intellectual contribution to the study and be prepared to take public responsibility for the work, ensure its accuracy, and be able to identify his/her contribution to the study [1]. However, a problem with the definition of authorship involves the subjectivity in what constitutes a 'substantial' contribution to the research or the manuscript. In fact, the precise threshold of involvement required to qualify for authorship remains unclear. As the real problem lies in defining what represents a 'substantial' contribution, means to quantify the actual work performed by individual authors have been proposed. In this regard it has been suggested [17] that substantial contribution to a publication consists of an important intellectual contribution without which a part of the work or even the entire work could not have been completed or the manuscript could not have been written [17].

According to the ICMJE [1] persons who do not qualify as an author include those who 'only' provide: (1) recruitment of patients to a trial, (2) general data collection, (3) obtaining samples for a study, (4) acquisition of funding, (5) general supervision of the research group by the department chairperson. Conversely, persons who significantly contributed to the paper but do not meet the four criteria for authorship should be listed in the acknowledgement section after obtaining their consent.

\section{Publishing individual contributions}

The ICMJE authorship guidance is intentionally broad and open to accommodate the diversity of scientific 
research and allow space for the specific editorial policies of individual journals [1]. However, many have requested a more structured authorship framework to improve consistency and clarity in authorship requirements. The best means to present the relationship between authorship and intellectual involvement in research remains an issue of ongoing debate. Currently, the ICMJE does not mandate that all authors communicate exactly what 'contributions' qualify them to be an author [1]. However, unless authorship reflects to what extent individual researchers have been intellectually involved in the work it will remain misleading regarding relative research merits. Honesty and openness in attribution ensures fairness in credit. Many editors argue that authorship criteria should be revised to request a contribution declaration, in order to fully capture deserving authorship and credit. Accordingly, to promote transparency and remove ambiguity on specific contributions, editors are now strongly encouraged to develop and implement contributorship policies in their journals [1]. As discussed, however, the question regarding the quality and quantity of contribution required to qualify an individual for authorship remains unresolved [1]. An interesting proposal in this regard suggests including contributorship badges. These badges are designed to fully capture the different types of collaboration in the submitted work that, otherwise, will be difficult to recognise with traditional credentials. Listing of contributors allows a more accurate and granular assessment of credit. In addition, this strategy provides additional insight on contributor-adjusted productivity [18]. Ideally, each ICMJE criterion should have at least one badge. Each badge includes a list of authors making a contribution to that specific role [18-20]. Others have proposed the value of assigning a numerical value to better evaluate the degree of relative contributions and, eventually, to create a contribution-specific index for each author to better assess research productivity [18-20].

Detailing authors' contributions informs the readers of the nature of the individual work and avoids diluting credits by precisely allocating merits. In multiauthored papers it is particularly important that authors state the specific role they played in the research. Each research project represents a significant amount of effort and, on average, the larger the number of authors the smaller percentage of effort for a given author. Other forms of contributions, not fulfilling criteria for authorship, may be recognised in the acknowledgement section or by listing these people as collaborators. This is an important issue considering the ever-increasing number of authors seen in recent publications that represents a paradigm shift resulting from team-work research [18-24]. Contributors credited as authors should take full responsibility and remain accountable for what is published [1, 18]. In this regard, contribution-adjusted credits can be further weighted by other factors to derive more effective parameters for measuring research produc- tivity. Currently, every co-author receives the exact amount of citation credit regardless of their contribution. Therefore, an 'author matrix' (including participation in ideas, work, writing and stewardship) has been proposed to 'quantify' individual contributions and roles in multi-authored papers [18-24].

\section{By-line location and hierarchy}

There is no adequate guidance for author sequence in the by-line. In fact, practices to clarify the relative merit of the different co-authors in a manuscript vary significantly among scientific disciplines [18-22]. For biomedical journals, the first author is the most important position, followed by the last author and then the second author. The first author is reserved for the person who made the largest contribution (investing most time in the project), usually the author who wrote the first draft of the paper. Then the sequence of authors tends to represent progressively lesser contributions [18]. Following this approach, where the sequence determines credit, the last author receives the least. Accordingly, the last position might be considered as a rather generous option. Actually, the last position is currently considered as very important in biomedical research and, in fact, it is frequently associated with the corresponding author or the guarantor of the entire work [18]. However, many argue that senior scientists should grab the pen (keyboard) more often, as writing remains essential for advancement in knowledge [19]. Senior authors have the responsibility to promote the academic career of new-generation scientists.

Many journals allow authors to declare that two or more individuals have made an 'equal contribution' to the research [21, 25-28]. In the last decade the percentage of articles with equal contribution statements has increased dramatically both in basic sciences and medical journals [25]. Notably, the designation of 'joint first authors' should be based on the quality and quantity of the work [21, 25-28]. Thus the "contributed equally" designation should be reserved to honestly reflect similar scientific contributions and not to inflate a curriculum vitae [21, 25-28]. Interestingly, the practice of listing two individuals as 'joint last author' is used less frequently but is steadily increasing. These publications should include a footnote clearly indicating that both authors contributed equally to the work [21, 25-28].

The corresponding author takes primary responsibility for communication with the journal during the submission, peer-review, publication and post-publication periods [1]. Currently, most journals require contact e-mail addresses from all listed authors who then will be contacted to inform them that the corresponding author submitted the paper. This ensures that they are aware that the paper has been submitted in their name. The systematic implementation of this electronic warning system paves the way to 
guarantee that the third authorship criterion has been met. Therefore, the policy now may be considered as a mere administrative requirement similar to signing a copyright transfer form.

The 'guarantor' of the study may be different from the first or corresponding author and frequently is the principal investigator or most senior person in the group. The guarantor takes full responsibility for the integrity of the work as a whole from inception to the published paper. Accordingly, the guarantor must be fully prepared to defend all parts of the research project and final manuscript. Guarantors vouching for the integrity of the entire work are of special value for multi-author articles particularly when many institutions are involved. All authors should also disclose potential conflicts of interest $[1,5]$. The ICMJE uniform conflict of interest disclosure has been recently updated and all authors should complete the corresponding standardised individual electronic document $[1,5]$. In particular, authors of sponsored studies should indicate that they had full access to the data and take complete responsibility for the accuracy and integrity of the analysis. This is important as the roles and interests of different stakeholders may remain elusive or misleading in this type of study [1].

The subjectivity and emotionality of authorship may explain why disputes among investigators are not uncommon. Authorship disputes amongst research teams should be avoided by deciding roles and responsibilities beforehand. Ideally, the order of the authors should be collectively decided by the research team at the onset of the project [29]. Then, the definitive order should be revised when the work is completed, taking into account the actual level of individual contributions [17]. Editors are unable to judge whether authors have met the authorship criteria. The COPE (Committee on Publication Ethics; www.publicationethics.org) guidelines are useful to solve publication disputes [9]. Editors should seek explanations and the signed agreement of all authors if there is a request for a change in the author list [1].

\section{Multi-authored articles}

Scientific collaboration has become increasingly important because the complexity of modern research involves different competencies [16]. Moreover, a large number of patients and centres may be required to adequately address clinically relevant questions [16]. In addition, multidisciplinary research groups offer the opportunity of cross-pollination [16]. Therefore, team-work is currently commonplace in biomedical research. Co-authorship is the most tangible result of multilateral scientific collaboration. Group (corporate) authorship has become increasingly common with variations in how individual authors and research group names are listed in the byline. Notably, citation impact is greater in papers with multiple authors coming from international co- operation. The problem of inflating publication and citation records of authors participating in multicentre studies has been a cause for concern [18]. This is due, at least in part, to collaboration-induced selfcitation [30]. Salami publications, or least publishable units strategies, are initiatives that inflate the number of publications on the same research project by dividing the work (that could have been presented in a single main paper) into smaller component parts, then publishing them as several different articles. Such strategies may be detected in some multicentre studies [30]. The use of co-author-adjusted citation indexes has been suggested to account for this phenomenon [30].

There is evidence that the number of co-authors per paper in medical literature has increased exponentially over time [22, 31]. The reason for this increase is probably multifactorial and includes increasing complexity of research, as discussed, but also author inflation. Inappropriate authorship is not ethical and eventually leads to diminishing the value of authorship, generating a situation where undeserved coauthors cannot take responsibility for the research [22, 31]. Interestingly, the correlation between research quality and number of authors is poor, suggesting that the component of author inflation plays a greater role than that of research complexity [31].

Until now the number of authors in the by-line was not considered in the evaluation of the relative academic merit of individual authors [3]. However, as a research project involves a defined amount of work, the larger the number of authors in a paper the less merit any given author deserves. Major efforts are made by some individuals whereas others contribute significantly less. The credit received by people doing the work becomes diluted by the inclusion of many authors with minor, if any, contributions. Eventually this 'free lunch' strategy undermines the value of being named on a scientific paper [32].

Authorship guidelines should be updated to adapt to the growing trend of collaborative research. The larger the number of authors the more opportunities for contentious arguments and disputes. Every author of a 'group authorship' work must meet the four criteria for authorship. Otherwise they should be identified just as investigators or collaborators rather than authors [1]. Given the complexity and multiple tasks involved in current research it is clear that most authors cannot participate in every aspect of the work. Accordingly, specific responsibilities should be tied to different research roles. Authors should refrain from collaborating with colleagues whose quality or integrity may inspire concerns [1]. Last, but not least, with a growing number of authors it is increasingly difficult to identify those who may be held morally responsible should scientific misconduct be detected $[22,31]$. Holding everybody responsible is unfair to the researchers that are not guilty of misconduct. 
Breaches in authorship: from ghost to guest authors

Breaches in authorship are a form of deception. Guest or gift (honorary) and ghost (hidden) authors represent a form of authorship abuse that should not be permitted [33-37]. Ghost authorship is omitting authors that have made relevant contributions to a paper. Ghost authors provide contributions to a manuscript that do merit authorship but, for different reasons, are not included in the author byline. Some ghost authors may have major conflicts of interest or are paid by a commercial sponsor. This should be differentiated from ghost writing. Ghost writers are writing contributors to a manuscript that do not fulfil authorship criteria, but their contributions are not disclosed in the acknowledgements [17, 36]. Ghost writing is also an unethical practice as it keeps hidden the involvement in the manuscript. The concern is that writers hired by industry might influence the content of the publication or hide unwelcome results, which introduces potential bias that is obscured when relevant academic guest authors are accredited with authorship [17]. Professional medical writers should follow ethical publication practices and should openly disclose their involvement in the acknowledgement section [36].

The inclusion of individuals with minimal or no input reflects 'loose authorship' practices [33-37]. Guest, gift or honorary authorship is defined as coauthorship awarded to people who do not meet the authorship criteria and have not contributed substantially to taking public responsibility for the work [1]. This may be offered in the belief that the prestige of a scientifically respected person will increase the likelihood of publication or the impact of the work [29]. Oftentimes, a well-known academic senior name is used to conceal ghost authors with industry-related conflicts of interest [29]. Both the gift author and the remaining co-authors may benefit from this practice (a win-win situation) that, nevertheless, remains unethical. The increased pressure to publish among scholars seeking promotion and career advancement (the "publish or perish" culture) may also help to explain these practices. This pressure explains why some researchers accept 'gift' authorship in papers to which they have not contributed intellectually. This abuse in authorship devalues the merit of being named as an author in a scientific paper. As previously discussed, quantitative contribution helps to prevent granting undeserved credits to guest authors who take away well-deserved credits from the authors who actually did the work [37-40].

Studies suggest that breaches of authorship guidelines are frequent. In a recent survey one-third of authors believed that they had been excluded from deserved authorship and a similar number declared that they had experienced pressure to include undeserved authors in their papers [20]. Another recent study of journals included in the Journals Citation Reports database suggested that $85 \%$ of them included in their policy guidance the requirement that authors should be accountable for the research as a whole, $32 \%$ explicitly prohibited guest or ghost authorship, but only $5 \%$ required authors to describe their individual contributions [25].

Acknowledgements We are grateful for the support and assistance of Michael Alexander and Margot Bolard, from the ESC Publications Department, at the European Heart House.

Author Contribution Authorship confers credit but also involves responsibility. Authors should be accountable and vouch for the integrity of the entire work. The Editors' Network of the ESC endorses the ICMJE recommendations on authorship and encourages individual NSCJ to adapt their editorial policies accordingly.

Conflict of interest F. Alfonso and Editors' Network and European Society of Cardiology (ESC) Task Force declare that they have no competing interests.

Open Access This article is distributed under the terms of the Creative Commons Attribution 4.0 International License (http://creativecommons.org/licenses/by/4.0/), which permits unrestricted use, distribution, and reproduction in any medium, provided you give appropriate credit to the original author(s) and the source, provide a link to the Creative Commons license, and indicate if changes were made. 


\section{Appendix}

Table 1 Editors in Chief and their journals

\begin{tabular}{|c|c|}
\hline Alban Dibra & Editor in Chief Revista Shqiptare e Kardiologjisë \\
\hline Albert Varga & Editor in Chief Cardiologia Hungarica \\
\hline Alexander Mrochek & Editor in Chief Cardiology in Belarus \\
\hline Alfonso Buendia Hernandez & Editor in Chief Archivos de Cardiologia de Mexico \\
\hline Andreas Flammer/François Mach & Editor in Chief Cardiovascular Medicine \\
\hline Anetta Undas & Editor in Chief Kardiologia Polska \\
\hline Anton Doubell & Editor in Chief SAHeart \\
\hline Ariel Cohen & Editor in Chief Archives of Cardiovascular Diseases \\
\hline Carlos Eduardo Rochitte & Editor in Chief Arquivos Brasileiros de Cardiologia \\
\hline Carmen Ginghina & Editor in Chief Romanian Journal of Cardiology \\
\hline Çetin Erol & Editor in Chief Anatolian Journal of Cardiology \\
\hline Chu-Pak Lau & Editor in Chief Journal of the Hong Kong Colleage of Cardiology \\
\hline Claes Held & Editor in Chief Svensk Cardiologi \\
\hline Dario Echeverri & Editor in Chief Revista Colombiana de Cardiologia \\
\hline Dilek Ural & Editor in Chief Archives of the Turkish Society of Cardiology \\
\hline Dimitris Tousoulis & Editor in Chief Hellenic Journal of Cardiology \\
\hline Eckart Fleck & Editor in Chief Der Kardiologe \\
\hline Evgeny Shlyakhto & Editor in Chief Russian Journal of Cardiology \\
\hline Faiq Guliyev & Editor in Chief Azerbaijan Journal of Cardiology \\
\hline Faouzi Addad & Editor in Chief Revue Tunisienne de Cardiologie \\
\hline Gerd Heusch & Editor in Chief Basic Research in Cardiology \\
\hline Germanas Marinskis & Editor in Chief Seminars in Cardiovascular Medicine \\
\hline Giuseppe Di Pasquale & Editor in Chief Giornale Italiano di Cardiologia \\
\hline Ignacio Ferreira-González & Editor in Chief Revista Española de Cardiología \\
\hline Ismael Guzman Melgar & Editor in Chief Revista Guatemalteca de cardiologia \\
\hline Izetbegovic & Editor in Chief Medicinski Zurnal \\
\hline Jan Piek & Editor in Chief Netherlands Heart Journal \\
\hline Jean-Jacques Monsuez & Editor in Chief Archives des maladies du cœur et des vaisseaux-Pratique \\
\hline Kanat Kabdrakhmanov & Editor in Chief Journal Terapevticheskiy vestnic \\
\hline Kjell Nikus & Editor in Chief Sydänääni (Heart Beat) \\
\hline Kurt Huber & Editor in Chief Austrian Journal of Cardiology \\
\hline Laila Haddour & Editor in Chief Revue Marocaine de Cardiologie \\
\hline Lino Goncalves & Editor in Chief Revista Portuguesa de Cardiologia \\
\hline Livio Dei Cas & Editor in Chief Journal of Cardiovascular Medicine \\
\hline Luc Pierard & Editor in Chief Acta Cardiologica \\
\hline Mahmoud Hassanein & Editor in Chief The Egyptian Heart Journal \\
\hline Mamanti Rogava & Editor in Chief Cardiology and Internal Medicine (Georgian International Society of Cardiomyopathy) \\
\hline María del Pilar Aguilar Passano & Editor in Chief Revista Uruguaya de Cardiologia \\
\hline Mario Ivanusa & Editor in Chief Cardiologia Croatica \\
\hline Michael Aschermann & Editor in Chief Cor et Vasa \\
\hline Michael Boehm & Editor in Chief Clinical Research in Cardiology \\
\hline Mikael Sander & Editor in Chief Cardiologisk Forum \\
\hline Nuray Enç & Editor in Chief Kardiyovaskuler Hemsirelik Dergisi \\
\hline Olaf Rødevand & Editor in Chief Hjerteforum \\
\hline Parounak Zelveian & Editor in Chief Armenian Journal of Cardiology \\
\hline Plamen Gatzov & Editor in Chief Bulgarian Journal of Cardiology \\
\hline Robert Hatala & Editor in Chief Cardiology Letters \\
\hline Slobodan Obradović & Editor in Chief Heart and Blood Vessels \\
\hline
\end{tabular}


Table 1 (Continued)

\begin{tabular}{l|l}
\hline Tzung-Dau Wang & Editor in Chief Acta Cardiologica Sinica \\
\hline Ulrike Fortmüller & Editor in Chief Cardio News \\
\hline Valentyn Shumakov & Editor in Chief Ukrainian Journal of Cardiology \\
\hline Yangsoo Jang & Editor in Chief Korean Circulation Journal \\
\hline Zlatko Fras & Editor in Chief Slovenska kardiologija
\end{tabular}

\section{References}

1. The International Committee of Medical Journals Editors. Recommendations for the conduct, reporting, editing, and publication of scholarly work in medical journals. http:// www.icmje.org/recommendations.

2. Lüscher TF. The codex of science: honesty, precision, and truth-and its violations. Eur Heart J. 2013;34:1018-23.

3. Alfonso F, Ambrosio G, Pinto FJ, Ector H, Vardas P, Kulakowski P, Timmis A, Editors' Network ESC Task Force. European Society of Cardiology national cardiovascular journals: the 'Editors' Network'. Eur Heart J. 2010;31:26-8.

4. Mills P, Timmis A, Huber K, Ector H, Lancellotti P, Masic I, Ivanusa M, Antoniades L, Aschermann M, Laucevicius A, Mustonen P, Artigou JY, Vardas P, Stefanadis C, Chiarello M, Bolognese L, Ambrosio G, van der Wall EE, Kułakowski P, Pinto FJ, Apetrei E, Oganov RG, Kamensky G, Lüscher TF, Lerch R, Haouala H, Sansoy V, Shumakov V, Tajer CD, Lau CP, Márquez M, Krittayaphong R, Arai K, Alfonso F. The role of European national journals in education. Heart. 2009;95:e3.

5. Alfonso F, Timmis A, Pinto FJ, Ambrosio G, Ector H, Kulakowski P, Vardas P, Editors' Network European Society of Cardiology Task Force. Conflict of interest policies and disclosure requirements among European Society of Cardiology National Cardiovascular Journals. Eur Heart J. 2012;33:587-94.

6. Alfonso F. Data Sharing. Editors' NetworkEuropean Society of Cardiology Task Force ; Editors' Network European Society of Cardiology TaskForce. Eur Heart J. 2017;38:1361-3.

7. Council of Science Editors. White paper on publication ethics. CSE's white paper on promoting integrity in scientific journal publications. 2012. http://www. CouncilScienceEditors.org.

8. World Association of Medical Editors. WAME professionalism code of conduct. The new WAME professionalism code of conduct for medical journal editors. http://www.wame. org.

9. Committee On Publication Ethics. COPE. Code of conduct and best practice guidelines for journal editors. http:// publicationethics.org/resources/guidelines.

10. Stephenson J. ICMJE: All authors of medical Journal articles have "responsibility to stand by the integrity of the entire work". JAMA. 2013;310:1216.

11. No author listed. The Lancet. Authorship and accountability. Lancet. 2013;382:744.

12. Goodman NW. Survey of fulfillment of criteria for authorship in published medical research. BMJ. 1994;309:1482.

13. Rennie D, Flanagin A. Authorship! Authorship! Guests, ghosts, grafters, and the two-sided coin. JAMA. 1994;271:469-71.

14. Rennie D, Yank V, Emanuel L. When authorship fails. A proposal to make contributors accountable. JAMA. 1997;278:579-85.

15. Leonelli S. Locating ethics in data science: responsibility and accountability in global and distributed knowledge production systems. Philos Trans A Math Phys Eng Sci. 2016;374(2083).

16. Helgesson G, Eriksson S. Responsibility for scientific misconduct in collaborative papers. Med Health Care Philos. 2018;21:423-30.

17. Stocks A, Simcoe D, Toroser D, DeTora L. Substantial contribution and accountability: best authorship practices for medical writers in biomedical publications. Curr Med Res Opin. 2018;34:1163-8.

18. Clement TP. Authorship matrix: a rational approach to quantify individual contributions and responsibilities in multi-author scientific articles. Sci Eng Ethics. 2014;20:345-61.

19. Fairbairn S, Kelly L, Mahar S, Prosée R. Authorship: an evolving concept. Editorial coordinators. Health Learning, Research \& Practice, Wolkers and Kluber. http://wkauthorservices.editage.com/resources/files/ An_Evolving_Concept_in_Scientific_and_Medical_ Publishing.pdf.

20. Nylenna M, FagerbakkF, KierulfP.Authorship: attitudes and practice among Norwegian researchers. BMC Med Ethics. 2014;15:53.

21. Hess CW, Brückner C, Kaiser T, Mauron A, Wahli W, Wenzel UJ, Salathé M. Authorship in scientific publications: analysis and recommendations. Swiss Med Wkly. 2015;145:w14108.

22. Hwang SS, Song HH, Baik JH, Jung SL, Park SH, Choi KH, et al. Researcher contributions and fulfillment of ICMJE authorship criteria: analysis of author contribution lists in research articles with multiple authors published in radiology. International Committee of Medical Journal Editors. Radiology. 2003;226:16-23.

23. Hoen WP, Walvoort HC, Overbeke AJ. What are the factors determining authorship and the order of the authors' names? A study among authors of the Nederlands Tijdschrift voor Geneeskunde (Dutch Journal of Medicine). JAMA. 1998;280:217-8.

24. Wager E. Do medical journals provide clear and consistent guidelines on authorship? Med Gen Med. 2007;9:16.

25. Resnik DB, Tyler AM, Black JR, Kissling G. Authorship policies of scientific journals. J Med Ethics. 2016;42:199-202.

26. AkhabueE, LautenbachE. "Equal" contributions and credit: an emerging trend in the characterization of authorship. Ann Epidemiol. 2010;20:868-71.

27. Dotson B. Equal contributions and credit assigned to authors in pharmacy journals. Am J Pharm Educ. 2013;77:39.

28. Li Z, Sun YM, Wu FX, Yang LQ, Lu ZJ, Yu WF. Equal contributions and credit: an emerging trend in the characterization of authorship in major anaesthesia journals during a 10-yr period. PLoSONE. 2013;8:e71430.

29. Tarkang EE, Kweku M, Zotor FB. Publication practices and responsible authorship: a review article. J Public Health Africa. 2017;8:723.

30. Ioannidis JP. A generalized view of self-citation: direct, coauthor, collaborative, and coercive induced self-citation. JPsychosom Res. 2015;78:7-11. 
31. Chow DS, Ha R, Filippi CG. Increased rates of authorship in radiology publications: a bibliometric analysis of 142,576 articles published worldwide by radiologists between 1991 and 2012. AJR Am J Roentgenol. 2015;204:W52-W7.

32. Shapiro DW, Wenger NS, Shapiro MF. The contributions of authors to multiauthored biomedical research papers. JAMA. 1994;271:438-42.

33. Flanagin A, Carey LA, Fontanarosa PB, Phillips SG, Pace BP, Lundberg GD, Rennie D. Prevalence of articles with honorary authors and ghost authors in peer-reviewed medical journals. JAMA. 1998;280:222-4.

34. Laine C, Mulrow CD. Exorcising ghosts and unwelcome guests. Ann Intern Med. 2005;143:611-2.
35. Wislar JS, Flanagin A, Fontanarosa PB, Deangelis CD. Honorary and ghost authorship in high impact biomedical journals: a cross sectional survey. BMJ.2011;343:d6128.

36. Stretton S. Systematic review on the primary and secondary reporting of the prevalence of ghostwriting in the medical literature. BMJ Open. 2014;4:e4777.

37. Smith R. Let's simply scrap authorship and move to contributorship. BMJ.2012;344:e157.

38. Tilak G, Prasad V, Jena AB. Authorship inflation in medical publications. Inquiry. 2015;29:52.

39. Juyal D, Thawani V, Thaledi S, Prakash A. The fruits of authorship. Educ Health (Abingdon). 2014;27:217-20.

40. Fanelli $D$. Why growing retractions are (mostly) a good sign. Plos Med. 2013;10:e1001563. 